\title{
Genetic and Serological Diversity of Chlamydia trachomatis Strains Detected from Japanese Infants
}

\section{Kei Numazaki}

Division of International Infectious Diseases, Graduate School of Health and Welfare, International University of Health and Welfare, Nasushiobara, Tochigi, Japan

\section{Abstract}

Background: Classical fifteen serovars and variants of Chlamydia trachomatis were originally classified by the micro-immunofluorescence test which principally distinguished epitopes on the major outer-membrane protein (MOMP). The sequences of MOMP gene including four variable domains (VDs) have been determined for all classic 15 serovars. The PCR assay was used to amplify a large part of the MOMP gene (ompA or omp 1) including four VDs and then cataloged restriction fragment length polymorphism (RFLP) was used to identify the serovars from genotypes of $C$. trachomatis as reported previously.

Materials and Methods: Nasopharyngeal specimens were collected from 15 Japanese infants with pneumonia, from 1 month to 1 year old, during the period May 1990 to September 2013. Conjunctival swabs were also collected from 12 Japanese neonates under 1 month old with inclusion conjunctivitis during the same period. The specimens were collected and placed into Abbott LCR proprietary medium and then tested by PCR for typing. The sequencing strategy used was the double-stranded DNA cycle sequencing method.

Results: Applied to 15 reference strains, this PCR-RFLP procedure allowed us to determine 13 of the 15 serovars of C. trachomatis. Thirteen of 15 isolates of nasopharyngeal origin and 11 of 12 isolates of conjunctival origin could be un-equivocally assigned to one of the 15 reference serovars with a restriction endonuclease profile identical to that of the prototype. The typing of 15 nasopharyngeal isolates gave the following results: 11 as $\mathrm{E}, 2$ as $\mathrm{H}$, and 2 as unclassified serovars. The typing of 12 conjunctival isolates gave the following results: 5 as D, 4 as E, 1 as F, 1 as $\mathrm{H}$ and 1 as unclassified serovar. Among the unclassified serovars, one was B-like and the rest was D-like.

Discussion: The sequences of MOMP gene for all classic 15 serovars allowed the construction of restriction endonuclease cleavage-site maps that confirm the fragment-size patterns observed by electrophoresis. Sequencing the entire MOMP gene and cataloging the sequences of VDs of all serovars has confirmed the molecular basis of the serotyping procedure and provided a method for determining serovars by PCR-RFLP. Although geno-variants have also been reported for most serovars the PCR-RFLP method for typing allows quick and objective identification of serovars of $C$. trachomatis. Antigenic variations of $C$. trachomatis were also considered among the strains from nasopharyngeal and conjunctival origins.

\section{Introduction}

Chlamydia trachomatis is the leading cause of sexually transmitted infections (STI) worldwide. We have analyzed reference and clinical samples that has not previously been represented in C. trachomatis typing schemes $[1,2]$, to expand our knowledge of the global diversification of strain types (serovars) [3-6]. The samples resolved into unique serovars, compared to the gold standard single locus ompA (or omp1) genotyping. Phylogenetic analyses revealed distinct branches for the phenotypic diseases of lymphogranuloma venereum (LGV), urethritis and cervicitis, and a sub-branch for ocular trachoma [7].

Fifteen serovars and variants of $C$. trachomatis were originally classified by the micro-immunofluorescence (MIF) test which principally distinguished epitopes on the major outer-membrane protein (MOMP) [8]. C. trachomatis exists as classic 15 serovars such as A, B, Ba, C, D, E, F, G, H, I, J, K, L1, L2 and L3. Serotyping correlates well with the four variable domains (VDs of MOMP. The 15 classic serovars can be divided originally into two pathotypes. The ocular pathotypes including serovars A-C are associated with so-called classic trachoma which is still hyper-endemic in Africa, Asia, and South America. Trachoma is still the second major cause of blindness all over the world [9]. The sequences of MOMP gene including four VDs have been determined for all classic 15 serovars [10]. severe complications. 3001; E-mail: numazaki@iuhw.ac.jp and source are credited.

\section{Publication History:}

Received: August 27, 2019

Accepted: September 21, 2019

Published: September 23, 2019

\section{Keywords:}

Chlamydia trachomatis, Serotype, Genotype, Infantile pneumonia, Neonatal conjunctivitis Under the genital pathotypes, which causes STI, serovars D-K affect mainly the mucous membrane. It should be pointed out that in the literature, serovars $\mathrm{D}-\mathrm{K}$, together with serovars $\mathrm{A}-\mathrm{C}$, have been grouped into the so-called trachoma biovar. However, these two serovar groups affect the eye quite differently. Whereas the ocular serovars (A-C) cause chronic ocular infection, which may lead to blindness, the genital serovars (D-K) cause only transient, selflimiting infection in the conjunctival mucous membrane without

The PCR assay was used to amplify a large part of the MOMP gene (ompA or omp1) including four VDs and then cataloged restriction fragment length polymorphism (RFLP) was used to identify the

"Corresponding Author: Prof. Kei Numazaki, Division of International Infectious Diseases, Graduate School, Departments of Pediatrics and Infection Control, University Hospital, International University of Health and Welfare 537-3 Iguchi, Nasu-shiobara, Tochigi 329-2763, Japan, Tel: +81-287-39-3060, Fax: +81-287-39-

Citation: Numazaki K (2019) Genetic and Serological Diversity of Chlamydia trachomatis Strains Detected from Japanese Infants. Int J Pediatr Neonat Care 5: 159. doi: https://doi.org/10.15344/2455-2364/2019/159

Copyright: (C) 2019 Numazaki. This is an open-access article distributed under the terms of the Creative Commons Attribution License, which permits unrestricted use, distribution, and reproduction in any medium, provided the original author 
Citation: Numazaki K (2019) Genetic and Serological Diversity of Chlamydia trachomatis Strains Detected from Japanese Infants. Int J Pediatr Neonat Care 5: 159. doi: https://doi.org/10.15344/2455-2364/2019/159

serovars from genotypes of C. trachomatis from nasopharyngeal and conjunctival swabs obtained from Japanese infants and neonates with pneumonia and conjunctivitis as reported previously $[1,8]$. In this study I detected the presence of unclassified serovars of $C$. trachomatis, by means of PCR-RFLP analysis and sequencing of amplified DNA, obtained from Japanese infants.

\section{Materials and Methods}

\section{C. trachomatis reference and clinical samples}

Nasopharyngeal specimens were collected from 15 neonates and infants with pneumonia from 1 month to 1 year old, during the period May 1990 to September 2013. Conjunctival swabs were also collected from 12 neonates under 1 month old with inclusion conjunctivitis during the same period. Diagnosis of pneumonia was based on clinical findings and radiologic confirmation (Figure 1 and Figure 2). Clinical samples were analyzed including the 23 reference strains: A/ SA-1, A/HAR-13, B/TW-5/OT, Ba/AP-2/OT, B/ TW-5/OT, B/Jali-20/ OT, C/TW-3/OT, D/ UW-3/CX, D/IC-Cal-8,Da/TW-448, E/Bour, F/ IC-Cal3, G/UW-57/CX, H/UW-4/CX, I/UW-12/UR, Ia/UW-202, J/ UW-36/CX, Ja/UW-92, K/UW-36/CX, L $/ 1440, \mathrm{~L}_{2} / 434, \mathrm{~L}_{2 \mathrm{a}} / \mathrm{UW}-396$, $\mathrm{L}_{3} / 404$.

\section{RFLP pattern analysis of the amplified MOMP gene for genotyping}

The PCR assay to amplify ompA gene and RFLP analysis were used to detect and distinguish serotypes from genotypes of $C$. trachomatis as reported previously $[1,2]$. Briefly, an approximately $1 \mathrm{~kb}$ fragment of the ompA gene was amplified using primers SERO1A (5'-ATG AAA AAA CTC TTG AAA TCG G-3') and SERO2A, (5'-TTT CTA GAT CTT CAT TCT TGT T-3'). The reaction was performed in a

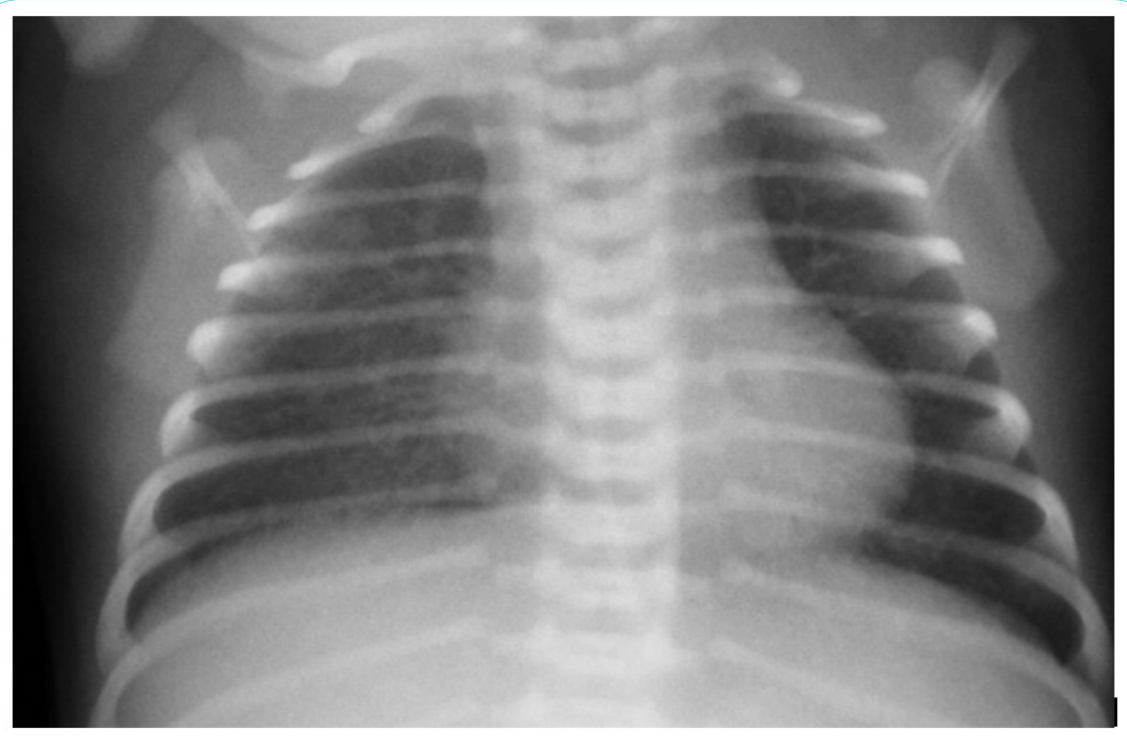

Figure 1: Chest radiograph of C. trachomatis pneumonia

A chest radiograph of an infant with C. trachomatis pneumonia which revealed interstitial pneumonitis. Streaky shadow and reticulogranular infiltrates over the whole lung without hyperinflation were recognized.

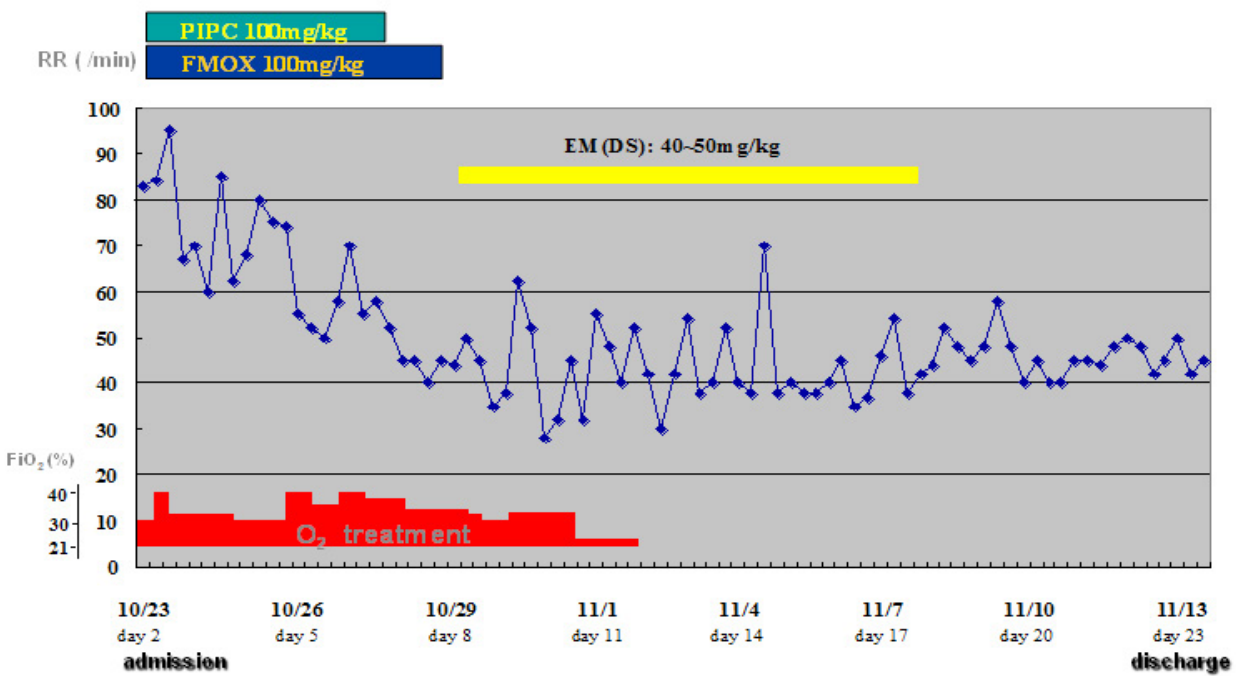

Figure 2: Clinical course of the C. trachomatis pneumonia.

A 2-day-old full-term male presented with mild left eye discharge. There had been no fever and examination showed a wellappearing baby with no respiratory distress. On day 3 fever, tachypnea and cyanosis appeared on this infant. His pulse rate was $80-100 / \mathrm{min}$ and $\mathrm{SpO}_{2}$ was $90 \%$ in room air. The infant was treated with a course of antibiotics including a macrolide and his respiratory condition was improved. 
Citation: Numazaki K (2019) Genetic and Serological Diversity of Chlamydia trachomatis Strains Detected from Japanese Infants. Int J Pediatr Neonat Care 5: 159. doi: https://doi.org/10.15344/2455-2364/2019/159

Page 3 of 5

final volume of $90 \mu \mathrm{l}$ containing $1.5 \mathrm{mM} \mathrm{MgCl}, 0.05 \mathrm{mM}$ of each deoxynucleotide triphosphate, $0.32 \mu \mathrm{M}$ of each primer, $2 \mathrm{U}$ of Taq DNA polymerase (Invitrogen Corporation, Brazil), and $10 \mu \mathrm{l}$ of clinical specimen. Cycling conditions began with an initial $7 \mathrm{~min}$ denaturation step at $94^{\circ} \mathrm{C}$, followed by 40 cycles of denaturation at $95^{\circ} \mathrm{C}$ for $1 \mathrm{~min}$, annealing at $45^{\circ} \mathrm{C}$ for $3 \mathrm{~min}$, and extension at $72^{\circ} \mathrm{C}$ for $3 \mathrm{~min}$. An additional 7 -min extension at $72^{\circ} \mathrm{C}$ was performed at the end of the 40 cycles. At the first step, $1.4 \mathrm{kbp}$ DNA fragments that is larger than a full length of the ompA gene was amplified. At the second step for nested PCR, $1.2 \mathrm{kbp}$ DNA fragment, a full length of ompA gene was amplified.

Genotyping was performed by Hinf I, Hind III, Cfo I and Hha I restriction analysis of amplified ompA. The precipitated and purified DNA from the remaining $90 \mu \mathrm{L}$ of PCR product was used for RFLP analysis with restriction enzyme, was prepared in a $20 \mu \mathrm{L}$ reaction mixture containing $3 \mu \mathrm{g}$ of purified DNA, $15 \mathrm{U}$ of enzyme, and $2 \mu \mathrm{L}$ of $10 \mathrm{x}$ buffer provided with the enzyme and mili $\mathrm{Q}$ water $q s$, and was incubated overnight at $37^{\circ} \mathrm{C}$. After inactivation of the enzyme at $65^{\circ} \mathrm{C}$ for 10 minutes, the product was electrophoresed through a $3 \%$ agarose gel in an electrophoresis apparatus (LKB, Pharmacia Sweden), stained with ethidium bromide and visualized under an UV transilluminator. (UVP, UK).

Products were electrophoresed through a polyacrylamide gel (acrylamide/bisacrylamide, 29:1; $12 \mathrm{~V} / \mathrm{cm}$ for $1.5 \mathrm{~h}$ ) to enable identification of serovars B/Ba, D, E, F, G, K, L1, L2, and C complex (C, J, H, I, and L3). Serotypes C and J were differentiated after digestion with Hinf I. Serotypes H, I, and L3 were separated with $C f o$ I digestion. Each ompA genotype was defined by testing a reference strain representing each of the 20 serovars. Comparison of the RFLP profiles of each clinical isolate with those of the reference strains was performed to assign a serovar from the genotype of each clinical isolate. Samples unclassified by PCR-RFLP were sequenced and compared with prototype strains. The ompA DNA sequences of unclassified strains were also compared with the prototype strains, B/ TW-5/OT, B/Jali-20/OT, Ba/AP-2/OT, D/ UW-3/CX and D/IC-Cal-8.

Clinical specimen collection was performed by the author's responsibilities under the agreement based on ethical guidelines on clinical research and the Helsinki Declaration. The study plan was approved by the Research Ethics Committee of International University of Health and Welfare Graduate School.

\section{Results}

Applied to 15 reference strains, this PCR-RFLP procedure allowed us to determine 13 of the 15 serovars of $C$. trachomatis. The digested PCR products showed two or three major fragments upon electrophoresis in a $2 \%$ agarose gel. Nine patterns were recognized with $H$ ha $\mathrm{I}$, four with Hind III and six with Hinf I. The B and Ba serovars, however, could not be separated by this method. The possibility that clinical isolates frequently have variant patterns was explored by analyzing clinical isolates which were found by culture and antigen detection by EIA to contain Chlamydia species. Thirteen of 15 isolates of nasopharyngeal origin and 11 of 12 isolates of conjunctival origin could be un-equivocally assigned to one of the prototype.

The typing of 15 nasopharyngeal isolates gave the following results: 11 as E, 2 as H, and 2 as unclassified serovars. The typing of 12 conjunctival isolates gave the following results: 5 as D, 4 as E, 1 as F, 1 as $\mathrm{H}$ and 1 as unclassified serovar (Table 1 and Table 2). Among the unclassified serovars, two groupings were identified by PCR-RFLP analysis, one was B-like and the rest was D-like. Two unclassified strains showed a type D pattern with Hha I, B, Ba, D, F, G and $\mathrm{L}_{1}$ patterns with Hind III and $\mathrm{B}, \mathrm{Ba}, \mathrm{E}, \mathrm{L}_{1}$ and $\mathrm{L}_{2}$ patterns with Hinf I. One showed $\mathrm{B}, \mathrm{Ba}$ and $\mathrm{E}$ patterns with Hha I, D with Hinf I and the same patterns as the former with Hind III. The B-like strain was identical to each other, the major sequence differences compared to serotype $\mathrm{B}$ occurred in VD1.

\begin{tabular}{|c|c|}
\hline Type E & 11 \\
\hline Type H & 2 \\
\hline Unclassified & 2 \\
\hline
\end{tabular}

\begin{tabular}{|l|l|}
\hline Type D & 5 \\
\hline Type E & 4 \\
\hline Type F & 1 \\
\hline Type H & 1 \\
\hline Unclassified & 1 \\
\hline
\end{tabular}

Table 2: Identified Serovars of C. trachomatis from 12 Neonates with Chlamydial Inclusion Conjunctivitis.

Comparison of the ompA gene sequences revealed five nucleotide changes, which gave rise to two amino acid alternations in VD1, a single nucleotide change which resulted in an amino acid substitution in VD2 and a single nucleotide change which resulted in no amino acid substitution in VD3. The VD2 and VSD regions of the ompA gene sequence were identical to those in the case of B/Jali-20/OT, which was isolated from a patient with trachoma. In B-like strain, the amino acid sequence of VD1 was identical to that in Ba/AP-2/ OT. Comparison of the ompA gene sequences of the D-like strains with that of D/UW-3/CX revealed two nucleotide changes, resulting in a single amino acid substitution in VS1. The ompA VDs nucleotide sequence was identical to that of D/IC-Cal-8.

\section{Discussion}

Early diagnosis and appropriate treatment of chlamydial infections may reduce the perinatal complications $[11,12]$. Sequencing the entire MOMP gene and cataloging the sequences of VDs of all serovars has confirmed the molecular basis of the serotyping procedure and provided a method for determining serovars by PCR-RFLP [1,2]. Genovariants have also been reported for most serovars. The PCRRFLP method for typing allows quick and objective identification of serovars of C. trachomatis [3,13]. C. trachomatis serovars of A B, Ba and $\mathrm{C}$ have been predominantly associated with endemic trachoma [1]. In contrast to urogenital chlamydial infection, trachoma is a household disease that has disappeared in many parts of the world because of improved living conditions and hygiene.

The ompA gene PCR- RFLP analysis has some weak points, such as the emergence of atypical restriction patterns due to mixed-genotype infections, artifacts from the enzymatic digestion, and ambiguities due to polymorphisms in the restriction sites or ompA recombinants [10]. The resolution of such atypical patterns requires cumbersome and time-consuming analysis and/or additional runs with different restriction enzymes.

The serovars, D, E, F and $\mathrm{H}$, were similar to those reported in other studies. However, there may be no clear pathogenic distinction between the serovars of endemic trachoma and STI (Figure 3). Unclassified 
Citation: Numazaki K (2019) Genetic and Serological Diversity of Chlamydia trachomatis Strains Detected from Japanese Infants. Int J Pediatr Neonat Care 5: 159. doi: https://doi.org/10.15344/2455-2364/2019/159

Page 4 of 5

serovars may be new strains or serovariants. There was not enough evidence to be sure that these unclassified clinical isolates were indistinguishable and represented a clone. DNA sequencing or other molecular biological assays seemed to be necessary to analyze unclassified strains. Trachoma strains but not genital isolates carry a deletion or frame shift mutation in a variable region encoding genes for tryptophan synthesis. In subjects infected with serotype E, a T-cell epitopes in VD 3 is recognized significantly less often than in subjects infected with other serotypes of self-limiting follicular conjunctivitis.

Additionally, on the basis of amino acid sequence homology, the classic 15 serovars of $C$. trachomatis have been classified into another 3 genetic groups: group B (B, D, E, L1 and L2), group C (A, C, H, I, J, K, L1 and L3) and an intermediate group (F and G). Serovars D-K are commonly associated with urogenital infections and perinatal conjunctivitis or pneumonia worldwide [11]. In women a broad spectrum of clinical manifestations can be present due to urogenital C. trachomatis infections including urethritis and cervicitis and if left untreated, the ascending infection may cause secondary complications in the upper genital tract, including pelvic inflammatory disease and infertility $[9,14]$. Serovars L1-L3 are associated with LGV, a systemic disease most prevalent in tropical and subtropical areas. Nevertheless, several outbreaks among homosexual male populations in western countries have been reported recently, indicating the merging role of LGV $[15,16]$.

Currently C. trachomatis has evolved to include 19 serovars based on antibody typing of MOMP with over 60 ompA genotypes [7], the gold standard typing technique for all Chlamydiaceae spp. Ocular infections include trachoma, a chronic ocular disease, and neonatal inclusion conjunctivitis, an infection acquired during passage through a C. trachomatis-infected birth canal. Urogenital strains cause not only ocular infections, which usually present as unilateral conjunctivitis, but also can ascend from the endocervix to cause sequelae such as pelvic inflammatory disease, infertility and ectopic pregnancy. Rectal infections can progress to proctitis and inguinal syndrome [17]. While the later is caused primarily by the LGV strains $\mathrm{L}_{1-3}, \mathrm{~L}_{2} \mathrm{a}, \mathrm{L}_{2} \mathrm{~b}$, and $\mathrm{L}_{2} \mathrm{c}$, the former can be caused by most C. trachomatis strains, although strains $\mathrm{B}, \mathrm{Ba}$, and $\mathrm{C}$ are usually not detected in the urethra, endocervix or rectum [18-20]. Strain A is the only strain that is confined to the ocular mucosa [9] .

Although ompA genotyping can be informative, the gene represents a mere $0.1 \%$ of the genome and is subject to immune selective pressure and recombination $[10,21,22]$. Partial and whole genome sequencing (WGS) have added considerably to our knowledge of the diversity of C. trachomatis and evidence for recombination [23]. Patients infected with C. trachomatis have significant risk of being infected with $U$. urealyticum and HIV, suggesting screening of $C$. trachomatis along with other STIs. Further, genotyping studies are required to understand the geographical distribution and introduction of new serovar in the community [20,24-26].

\section{Conclusions}

The sequences of MOMP gene for all 15 classic serovars allowed the construction of restriction endonuclease cleavage-site maps that confirm the fragment-size patterns observed by electrophoresis. Sequencing the entire MOMP gene and cataloging the sequences of VDs of all serovars has confirmed the molecular basis of the serotyping procedure and provided a method for determining serovars by PCR-RFLP. Although geno-variants have also been reported for most serovars the PCR-RFLP method for typing allows quick and objective identification of serovars of C. trachomatis. There maybe no clear ocular pathogenic distinction between the serovars of endemic trachoma and those associated with STI. Antigenic variations of $C$. trachomatis were also considered among the strains from nasopharyngeal and conjunctival origins.

\section{Acknowledgments}

The author express the gratitude to Masami Ikehata and Hideomi Asanuma at the Department of Pediatrics, Sapporo Medical University School of Medicine, Japan, for their valuable technical assistance and comments.

\section{Ocular Cycle}

\section{Conjunctiva $\rightarrow$ Conjunctiva \\ Trachoma \\ Neonatal Conjunctiva Inclusion Conjunctivitis Infantile Pneumonia}

$\uparrow \downarrow$

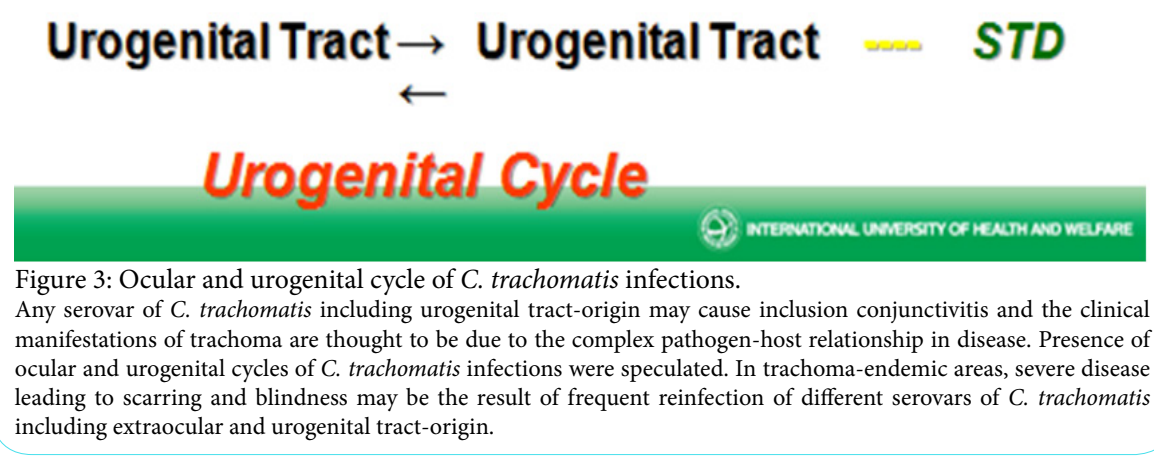


Citation: Numazaki K (2019) Genetic and Serological Diversity of Chlamydia trachomatis Strains Detected from Japanese Infants. Int J Pediatr Neonat Care 5: 159. doi: https://doi.org/10.15344/2455-2364/2019/159

Page 5 of 5

\section{Competing Interests}

The author declare no competing interests.

\section{References}

1. Numazaki K, Ikehata M, Chiba S, Suzuki K, Hashimoto N, et al. (1998) Unclassified serovars of Chlamydia trachomatis isolated from Japanese infants. Clin Microbiol Infect 4: 519-523.

2. Ikehata M, Numazaki K, Chiba S (2000) Analysis of Chlamydia trachomatis serovars in endocervical specimens derived from pregnant Japanese women. FEMS Immunol Med Microbiol 27: 35-41.

3. Petrovay F, Balla E, Németh I, Gönczöl E (2009) Genotyping of Chlamydia trachomatis from the endocervical specimens of high-risk women in Hungary. J Med Microbiol 58: 760-764

4. Dean D (2010) Pathogenesis of chlamydial ocular infections in Duane's Foundations of Clinical Ophthalmology.

5. Danby CS, Cosentino LA, Rabe LK, Priest CL, Damare KC, et al. (2016) Patterns of extragenital Chlamydia and Gonorrhea in women and men who have sex with men reporting a history of receptive anal intercourse. Sex Transm Dis 43: 105-109.

6. Molano M, Meijer CJ, Morre SA, Pol R, van den Brule AJ, et al. (2004) Combination of PCR targeting the VD2 of omp1 and reverse line blot analysis for typing of urogenital Chlamydia trachomatis serovars in cervical scrape specimens. J Clin Microbiol 42: 2935-2939.

7. Peuchant O, Touati A, Sperandio C, Hénin N, Laurier-Nadalié C, et al. (2016) Changing pattern of Chlamydia trachomatis strains in Lymphogranuloma Venereum outbreak, France, 2010-2015. Emerg Infect Dis 22: 1945-1947.

8. Molano M, Meijer CJ, Morre SA, Pol R, van den Brule AJ, et al. (2004) Combination of PCR targeting the VD2 of omp1 and reverse line blot analysis for typing of urogenital Chlamydia trachomatis serovars in cervical scrape specimens. J Clin Microbiol 42: 2935-2939.

9. Somboonna N, Mead S, Liu J, Dean D (2008) Discovering and differentiating new and emerging clonal populations of Chlamydia trachomatis with a novel shotgun cell culture harvest assay. Emerg Infect Did 14: 445-453.

10. Joseph SJ, Li B, Ghonasgi T, Qin ZC, Dean D, et al. (2014) Direct amplification, sequencing and profiling of Chlamydia trachomatis strains in single and mixed infection clinical samples. PLoS one 49: e99290.

11. Numazaki K (2004) Current problems of perinatal Chlamydia trachomatis infections. J Immune Based Ther Vaccines 2: 4.

12. Numazaki K, Asanuma H, Niida Y (2003) Chlamydia trachomatis infection in early neonatal period. BMC Infectious Diseases 3: 2 .

13. Gita S, Suneeta M, Anjana S, Niranjan N, Sujata M, et al. (2011) C. trachomatis in female reproductive tract infections and RFLP-based genotyping: a 16year study from a tertiary care hospital. Infect Dis Obstet Gynecol 2011: 548219.

14. Menon S, Timms P, Allan JA, Alexander K, Rombauts L, et al. (2015) Human and pathogen factors associated with Chlamydia trachomatis-related infertility in women. Clin Microbiol Rev 28: 969-985.

15. Timen A, Hulscher MEJL, Vos D, van de Laar MJW, Fenton KA, et al. (2008) Control measures used during Lymphogranuloma Venereum outbreak, Europe. Emerg Infect Dis 14: 573-578.

16. McLean CA, Stoner BP, Workowski KA (2007) Treatment of lymphogranuloma venereum. Clin Infect Dis 3: 147-152

17. Sethi G, Allason-Jones E, Richens J, Annan NT, Hawkins D, et al. (2009) Lymphogranuloma venereum presenting as genital ulceration and inguinal syndrome in men who have sex with men in London, UK. Sex Transm Infect 85: $165-170$.

18. Seth-Smith HM, Harris SR, Skilton RJ, Radebe FM, Golparian D, et al. (2013) Whole-genome sequences of Chlamydia trachomatis directly from clinical samples without culture. Genome Res 5: 855-866

19. Labiran C, Marsh P, Zhou J, Bannister A, Clarke IN, et al. (2016) Highly diverse MLVA-ompA genotypes of rectal Chlamydia trachomatis among men who have sex with men in Brighton, UK and evidence for an HIV-related sexual network. Sex Transm Infect 92: 299-304.

20. Danby CS, Cosentino LA, Rabe LK, Priest CL, Damare KC, et al. (2016) Patterns of extragenital Chlamydia and Gonorrhea in women and men who have sex with men reporting a history of receptive anal intercourse. Sex Transm Dis 43: 105-109.
21. Joseph SJ, Didelot X, Gandhi K, Dean D, Read TD, et al. (2011) Interplay of recombination and selection in the genomes of Chlamydia trachomatis. Biol Direct 6: 28.

22. Joseph SJ, Didelot X, Rothschild J, de Vries HJC, Morré SA, et al. (2012) Population genomics of Chlamydia trachomatis: insights on drift, selection recombination, and population structure. Mol Biol Evol 29: 3933-3946.

23. Batteiger BE, Wan R, Williams JA, He L, Ma A, et al. (2014) Novel Chlamydia trachomatis strains in heterosexual sex partners, Indianapolis, Indiana, USA. Emerg Infect Dis 20: 1841-1847.

24. Isaksson J, Gallo Vaulet L, Christerson L, Ruettger A, Sachse K, et al (2016) Comparison of multilocus sequence typing and multilocus typing microarray of Chlamydia trachomatis strains from Argentina and Chile. J Microbiol Methods 127: 214-218.

25. Schillinger JA, Katz BP, Markowitz LE, Braslins PG, Shrier LA, et al. (2016) Genotype-specific concordance of Chlamydia trachomatis genital infection within heterosexual partnerships. Sex Transm Dis 43: 741-749.

26. Smelov V, Vrbanac A, van Ess EF, Noz M, Wan R, et al. (2017) Chlamydia trachomatis strain types have diversified regionally and globally with evidence for recombination across geographic divides. Front Microbiol 8 : 2195. 